\title{
O ATIVISMO DOS FUNDOS DE PENSÃO E A QUALIDADE DA GOVERNANÇA CORPORATIVA ${ }^{1}$
}

\section{ACTIVISM OF PENSION FUNDS AND CORPORATE GOVERNANCE QUALITY}

\author{
FÁBIO RIBERI PUNSUVO \\ Mestre em Administração de Empresas pela \\ Universidade Presbiteriana Mackenzie - SP \\ E-mail: frp.punsuvo@globo.com
}

\author{
EDUARDO KAZUO KAYO \\ Professor Doutor Adjunto do Programa de Pós-Graduação \\ em Administração de Empresas \\ da Universidade Presbiteriana Mackenzie - SP \\ E-mail: eduardo.kayo@mackenzie.br
}

LUCAS AYRES BARREIRA DE CAMPOS BARROS

Professor Doutor Assistente do Programa de Pós-Graduação em Administração de Empresas

da Universidade Presbiteriana Mackenzie - SP

E-mail: lucasayres@yahoo.com.br

\section{RESUMO}

Os Fundos de Pensão são investidores institucionais de grande relevância para o mercado de capitais, tanto no exterior quanto no Brasil. À medida que as participações acionárias desses fundos crescem, também cresce a preocupação de se monitorar a atuação dos gestores das empresas que recebem os recursos. Utilizando a prerrogativa de grandes acionistas, os fundos de pensão podem passar a exercer essas atividades de monitoração de forma mais ativa. Assim, o objetivo principal deste artigo é analisar a relação entre a participaçã́o acionária dos fundos de pensão e a qualidade da governança corporativa das empresas em que aqueles investem seus recursos. O resultado da pesquisa mostra uma relação negativa entre essas variáveis, sugerindo um possível tradeoff entre a participação acionária e a governança corporativa como forma de alinhamento entre os fundos de pensão e as empresas.

Palavras-chave: Governança corporativa. Fundos de pensão. Ativismo. Criação de valor.

\section{ABSTRACT}

Pension funds are institutional investors of great relevance to capital markets in Brazil and abroad. As their ownership of public companies grows, pension funds tend to intensify their monitoring on the managers of incumbent companies. Using their prerogative as important shareholders, pension funds are able to exercise these monitoring activities more actively. Thus, the main objetive of this article is to analyze the relationship between the pension fund's ownership and the quality of corporate governance of the incumbent companies. Results show a negative relation between these variables, suggesting a possible tradeoff between ownership and corporate governance as mechanisms of alignment between pension funds and companies.

Keywords: Corporate governance. Pension funds. Activism. Value creation. 


\section{INTRODUC̣ÃO}

Dentre os diversos atores do mercado de capitais, destaca-se a participação dos investidores institucionais, sobretudo os fundos de pensão. Os fundos de pensão são considerados investidores de longo prazo, tendo em vista o horizonte de tempo relativo à formação de poupança dos seus participantes, pessoas físicas que aplicam seus excedentes almejando o recebimento de benefícios por ocasião de sua aposentadoria.

O processo de acumulação de poupança junto aos fundos de pensão tornou-os grandes investidores no mercado de renda variável. Como acionistas de um grande número de empresas, os fundos passaram a perceber a importância de estimular as empresas de capital aberto a adotarem práticas de governança corporativa. Exercendo o poder subjacente à sua posição de grandes acionistas, os fundos de pensão passam a reinvidicar modificações na forma de atuação das empresas nas quais investem, movimento esse conhecido como ativismo. Os fundos passam a perceber, também, a necessidade de desenvolver mecanismos que procurem alinhar os seus interesses aos dos gestores das empresas nas quais detêm participação acionária e, dessa forma, garantir o retorno de seus investimentos.
Como bem observam Monks e Minow (2004), os fundos de pensão possuem um incentivo natural a promover 0 ativismo, pois são gestores financeiros que devem rentabilizar adequadamente as contribuições dos participantes, sob risco de poderem lesar os seus clientes.

Dentro desse contexto, a governança corporativa surge como um conjunto de mecanismos que objetiva aumentar a confiabilidade nas relações entre os fundos de pensão e as empresas nais quais aqueles detenham participação acionária. O problema de pesquisa que se pretende responder, neste artigo, é: Qual a relação entre a participação acionária dos fundos de pensão e o nível de governança corporativa das empresas de capital aberto brasileiras? O objetivo principal é verificar se a participação acionária dos fundos de pensão exerce influência sobre a qualidade da governança corporativa das empresas. Além disso, em função de problemas de causalidade reversa sugeridos pela literatura, também é analisada a situação inversa, ou seja, procura-se analisar se a qualidade da governança corporativa influencia a participação acionária dos fundos de pensão.

\section{REFERENCIAL TEÓRICO}

\subsection{Governança corporativa}

De forma simplificada, a governança corporativa surge como uma forma de se mitigar os conflitos de interesse gerados pela separação entre propriedade e gestão de uma empresa. Esse problema é analisado por Jensen e Meckling (1976) no contexto da Teoria da Agência. Na clássica definição desses autores, o principal contrata o agente para desempenhar alguns serviços em nome daquele. Seria racional, portanto, que o agente buscasse sempre atender aos interesses do principal. Isso, porém, nem sempre ocorre porque os dois atores buscam maximizar suas próprias utilidades, que nem sempre são coincidentes. Faz-se necessário, então, buscar formas de se alinharem esses interesses. A governança corporativa é uma dessas formas.

Segundo Denis e McConnell (2003), a governança corporativa pode ser definida como um conjunto de mecanismos, institucionais e baseados pelo mercado, que induz os agentes a tomarem as decisões que maximizem o valor da companhia para os acionistas. Dessa forma, como sugerem Shleifer e Vishny (1986), a governança corporativa assegura o retorno dos investimentos realizados, reduz a ineficiência da alocação de recursos e incentiva os investidores a aumentarem suas participações na empresa.

Diferentes mecanismos de governança, internos ou externos, podem contribuir para o alinhamento dos interesses entre principal e agente. Um importante mecanismo externo, segundo Jensen (1988), é o comportamento do preço das ações, que pode limitar as ações discricionárias dos gestores uma vez que decisões mal tomadas podem reduzir o valor de mercado da empresa. Outro importante mecanismo externo, segundo Jensen (1988) e Denis e McConnell (2003), é a possibilidade de aquisições hostis, por meio das quais as empresas com desempenho insatisfatório podem ser ter seu controle tomado por outras empresas mais eficientes.

Além dos mecanismos externos de governança, a empresa dispõe de recursos internos com a mesma finalidade de alinhamento de interesses. Dentre esses mecanismos, um dos mais importantes é o Conselho de Administração. Entretanto, Shleifer e Vishny (1986) argumentam que, mesmo na hipótese dos acionistas elegerem os membros do conselho de administração, os indivíduos eleitos não necessariamente podem representar os interesses do principal. Daí a importância de um conselho que seja predominantemente formado por membros externos, garantindo, assim, a sua independência em relação aos diretores executivos. Ainda em relação ao Conselho de Adminitração, o seu tamanho também parece exercer influência sobre o desempenho das empresas. Pesquisando a relação entre o tamanho do conselho e o desempenho de empresas brasileiras por meio de uma regressão quadrática, Silveira, Barros e Famá (2003) apresentam evidências de que um tamanho intermediário (de quatro a oito conselheiros) alcançam melhores desempenho financeiros.

A estrutura de propriedade, também, é um mecanismo interno relevante. Segundo Denis e McConnell (2003), a estrutura acionária da empresa e o tamanho da posição de cada investidor são importantes mecanismos de governan- 
ça pois os investidores podem exercer algum controle sobre a empresa. Grandes acionistas, observam Denis e McConnell (2003), detêm os benefícios privados do controle. Dessa forma, são incentivados a monitorar os agentes $e$ possuem controle suficiente para exercer influência sobre a gestão da empresa. Essas são algumas características fundamentais para o papel ativista exercido pelos investidores institucionais, em geral, e pelos fundos de pensão, em particular. Vários estudos no Brasil já têm analisado questões relacionadas à influência da estrutura acionária. Silva (2002) analisou os efeitos da estrutura de controle e propriedade no valor de mercado, estrutura de capital e política de distribuição de dividendos de empresas no Brasil. Okimura (2003) estudou a relação entre a estrutura de propriedade e controle e o valor e desempenho das empresas não-financeiras privadas brasileiras. Uma questão que ainda merece atenção é a influência do tamanho da posição de cada investidor (especialmente os institucionais) sobre a qualidade da governança. Por isso, analisar a relação entre a participação dos fundos de pensão e a governança corporativa parece ser relevante.

\subsection{0 ativismo dos investidores institucionais}

Os investidores institucionais, conforme apresentado por Monks e Minow (2004), representam o grupo que contempla o maior volume de recursos de capital no mundo. Eles afirmam que um dos principais elementos para o entendimento do estágio atual da governança corporativa, passa pelo entendimento desse grupo.

Para compreender o surgimento do movimento de ativismo dos investidores, é importante introduzir as razões históricas para o despertar da governança corporativa, com atenção específica para os conflitos de agência que surgem naturalmente no ciclo de vida das empresas. As empresas nascem, em grande parte, como resultado de uma ação de seus fundadores, os quais acumulam, inicialmente, as funções de proprietários e gestores. O processo de evolução natural sugere que, obtendo sucesso, a empresa tende a crescer e, com o passar dos anos, a sucessão de comando na empresa deverá ocorrer. Em algum momento futuro, a separação da propriedade e gestão deverá ocorrer, incorporando na organização cada vez mais acionistas afastados da administração diária dos negócios. Os desdobramentos do processo de evolução da empresa poderá ensejar a aber- tura de capital, contribuindo para a dispersão crescente da propriedade, como em mercados como dos Estados Unidos e Reino Unido, países berços da moderna governança corporativa.

As práticas iniciais de governança corporativa foram estabelecidas como resposta a diversos problemas referentes ao relacionamento entre os acionistas e as empresas, a constituição dos conselhos de administração e a atuação da diretoria executiva.

Sobre os conselhos, Dalton et al. (1998) observaram que a atuação era figurativa, pois não agiam no sentido de defender os interesses dos proprietários acionistas, monitorando e controlando a direção. Muito pelo contrário, aprovavam matérias de interesses particulares. Quando avaliada a atuação da diretoria executiva, segundo Dalton et al. (1998), os acionistas manifestavam crescente descontentamento em relação a diversas práticas, como autobenefícios em escalas exageradas, gestão mais focada no curto prazo, estratégias defensivas e decisões não consensuais que exerciam impactos significativos na empresa.

Como resposta a esses conflitos, os investidores institucionais passaram a assumir uma postura mais ativa na condução de relações com as empresas nas quais detinham participação acionária. Gillan e Starks (1997), em pesquisa desenvolvida sobre o movimento do ativismo, apresenta o entendimento de que o ativismo do acionista pode ser observado como uma seqüência contínua de reações ao desempenho das empresas. Os fundos de pensão públicos, conforme apresentado por Gillan e Starks ( 1 997), são os mais propensos ao ativismo. Mesmo quando os fundos de pensão não são adeptos do ativismo, como alguns fundos de pensão privados, os gestores contratados para administrar seus recursos aparentemente conseguem influenciar a saída de alguns dirigentes em função de desempenho corporativo.

Embora o ativismo venha, muitas vezes, em resposta a fracos desempenhos da empresa, alguns estudos sugerem que nem sempre o ativismo possibilita uma recuperação. Wahal (1994), por exemplo, estuda a eficácia do ativismo dos fundos de pensão nas empresas alvo no período de 1987 a 1993, não encontrando evidências de melhoria no desempenho das ações a longo prazo. Entretanto, em contraste com outras instituições, os fundos de pensão não reduzem sua participação nas empresas com baixo desempenho.

\section{METODOLOGIA DA PESQUISA}

\subsection{Amostra, coleta e tratamento dos dados}

A amostra da pesquisa é não-probabilística, composta por empresas de capital aberto negociadas na BOVESPA no ano de 2004 que apresentem um nível mínimo de liquidez para garantir que os valores de mercado das empresas sejam representativos. São incluídas na amostra final as empresas que apresentem um índice de liquidez maior que
0,00 I \% no período compreendido entre janeiro de 2004 e abril de 2005, inclusive. Seguindo esse critério, a amostra seria composta por 119 empresas brasileiras. Considerando que algumas empresas passaram por processos de fusão e/ou fechamento de capital, a amostra final é reduzida para I 10 empresas. O índice de liquidez mede o nível de negociação do papel em relação ao mercado em que é transacionado e é dado pela Equação I: 


$$
I L=\left[\left(\sqrt{\frac{n}{N} * \frac{v}{V}}\right) * \frac{p}{P}\right] * 100
$$

em que, IL = Índice de Liquidez; $n=$ número de negócios com a ação verificados no mercado à vista (lote-padrão) no período analisado; $N$ = número total de negócios registrados no mercado à vista (lote-padrão) da BOVESPA no período analisado; $v=$ volume financeiro gerado pelos negócios com a ação no mercado à vista (lote-padrão) no período analisado; $V=$ volume financeiro total registrado no mercado à vista (lote-padrão) da BOVESPA no período analisado; $p=$ número de pregões do período analisado em que se constatou pelo menos I negócio com a ação no mercado à vista (lote-padrão) e $P=$ número total de pregões ocorridos no período analisado.

Uma vez estabelecida a amostra a ser pesquisada, são levantados os dados necessários para a construção operacional das variáveis. A construção das variáveis dependentes $\mathrm{e}$ independentes tem origem na consulta a diversas fontes de dados secundários. A construção do índice de governança corporativa, como proposto por Silveira (2004) utiliza dados coletados no Sistema de Divulgação Externa (DIVEXT) da CVM (Comissão de Valores Mobiliários) e dos websites institucionais de cada empresa analisada. A composição da carteira de renda variável dos fundos de pensão, também de fonte secundária, é fornecida pela Secretaria de Previdência Complementar e contempla a posição acionária vigente em 3I/I2/2004 (assume-se a participação dos fundos de pensão de forma direta ou indireta, isto é, por meio de instituições financeiras contratadas para tal propósito).

Uma vez coletados os dados e operacionalidas as variáveis, a análise é feita por meio de regressão múltipla, do tipo seção-cruzada (cross-section), pelo método dos mínimos quadrados ordinários.

\subsection{Problema de pesquisa, objetivos e hipóteses}

O problema de pesquisa que se pretende responder neste artigo é: Qual a relação entre a participação acionária dos fundos de pensão e o nível de governança corporativa das empresas de capital aberto brasileiras? O objetivo principal é verificar se a participação acionária dos fundos de pensão, supostamente ativistas no que diz respeito à gestão estratégica das empresas nas quais detêm participação, exerce influência sobre a qualidade da governança corporativa dessas últimas. Em função dos problemas de causalidade reversa que podem ocorrer na especificação do modelo empírico, são perseguidos dois objetivos específicos relacionados ao presente problema de pesquisa, a saber:

1. analisar a influência da participação acionária dos fundos de pensão sobre a qualidade da governança corporativa e

2. inversamente, analisar a influência da qualidade da governança corporativa sobre a participação acionária dos fundos de pensão.

Embora, neste artigo, sejam analisadas diversas variáveis que, supostamente, são determinantes da qualidade da governança corporativa, elas são assumidas como variáveis de controle. Com isso, o principal foco desta pesquisa é, tão-somente, a relação entre a participação dos fundos de pensão e a qualidade da governança corporativa.

No primeiro objetivo específico, a qualidade da governança corporativa representa a variável dependente, enquanto que a participação acionária dos fundos de pensão corresponde a uma das variáveis independentes. Em resumo, a reflexão relevante é avaliar se a qualidade da governança corporativa é explicada pela existência da participação acionária dos fundos de pensão, dentre outras variáveis. A hipótese inerente a esse problema é que exista uma relação negativa entre a participação dos fundos de pensão e a qualidade da governança corporativa. O segundo objetivo específico é inverso do primeiro. A participação acionária dos fundos de pensão representa a variável dependente, enquanto a qualidade da governança corporativa corresponde a uma das variáveis independentes. Em particular, o objetivo é avaliar se a participação acionária dos fundos de pensão é explicada pela qualidade da governança corporativa. Igualmente, a hipótese é de que se encontre uma relação negativa entre as variáveis.

Silveira (2004) indica e testa um conjunto de determinantes que influenciam a qualidade da governança corporativa. Partindo-se de seu modelo e acrescentando três variáveis adicionais (PART, PIBO e PIBX), o modelo estatístico geral, que se pretende analisar, é apresentado na Equação 2:

$$
\begin{aligned}
& I G O V_{i}=\alpha+\beta_{1} P_{A R T_{i}}+\beta_{2} \text { PIBO }_{i}+\beta_{3} \text { PIBX }_{i}+\beta_{4} C R E C_{i}+\beta_{5} \log (R E C)_{i}+\beta_{6} \text { TANG }_{i}+ \\
& \beta_{7} A D R_{i}+\beta_{8} B_{i} O V_{i}+\beta_{9} O W N_{i}+\beta_{10} D_{E S E M P_{i}}+\beta_{11} \text { PAYOUT }_{i}+\sum_{j=1}^{17} \delta_{j} I N D_{j i}+\sum_{l=1}^{5} \gamma_{j} I N D E N T_{l i}+\varepsilon_{i}
\end{aligned}
$$

Em função de problemas de causalidade reversa, testa-se, também, um modelo que assume a qualidade da governança como variável dependente, como mostra a Equação 3:

$$
\begin{aligned}
& \text { PART }_{i}=\alpha+\beta_{1} I G O V_{i}+\beta_{2} \text { PIBO }_{i}+\beta_{3} \text { PIBX }_{i}+\beta_{4} \text { CREC }_{i}+\beta_{5} \log (R E C)_{i}+\beta_{6} \text { TANG }_{i}+ \\
& \beta_{7} A D R_{i}+\beta_{8} B O V_{i}+\beta_{9} O W N_{i}+\beta_{10} D E S E M P_{i}+\beta_{11} \text { PAYOUT }_{i}+\sum_{j=1}^{17} \delta_{j} I N D_{j i}+\sum_{l=1}^{5} \gamma_{j} I N D E N T_{l i}+\varepsilon_{i}
\end{aligned}
$$




\subsection{Definição operacional das variáveis}

\subsubsection{Qualidade da governança corporativa}

A qualificação do nível de governança corporativa foi mensurada através da construção de um índice de governança corporativa $\left(\mathrm{IGOV}_{\mathrm{i}}\right)$, de acordo com a proposta de Silveira (2004), que calcula o índice a partir de um conjunto de 20 perguntas binárias e objetivas, apresentadas no Quadro I $\mathbf{0}$, cujas respostas foram obtidas exclusivamente a partir de dados secundários. As respostas positivas foram pontuadas, gerando como resultado um índice de governança entre 0 e 20.

\subsubsection{Participação acionária dos fundos de pensão nas empresas de capital aberto brasileiras}

Para a verificação da carteira de investimentos dos fundos de pensão (EFPC's) no segmento de renda variável, este artigo utiliza dados secundários retirados do Demonstrativo Analítico de Investimentos e Enquadramento de Aplicações (DAIEA) da Secretaria de Previdência Complementar (SPC).
O DAIEA apresenta, detalhadamente, a posição dos investimentos, contemplando os investimentos realizados diretamente pelas EFPC's e os investimentos realizados através de instituições financeiras contratadas pelas EFPC's para a realização de gestão de recursos terceirizada.

A variável que representa a participação acionária dos fundos de pensão nas empresas de capital aberto (PART $)$ foi calculada pela somatória da quantidade de ações detidas por todos os fundos de pensão dividida pelo número total de ações de cada empresa.

\subsubsection{Variáveis de controle}

Neste artigo, são assumidas como variáveis de controle todas aquelas testadas por Silveira (2004), além de duas outras adicionadas no presente artigo. Uma das variáveis acrescentadas e que não consta da pesquisa de Silveira (2004) é a participação da empresa no IBOVESPA (PIBO), representada por uma variável binária que assume o valor de I quando a empresa faz parte da composição do IBOVESPA e zero quando não participa. A segunda variável incluída é a participação da empresa no IBX (PIBX), também

\begin{tabular}{|c|c|c|}
\hline $\begin{array}{l}\text { Dimensão da Governança } \\
\text { Corporativa }\end{array}$ & \# & Perguntas para construção do Índice de Governança Corporativa \\
\hline \multirow[t]{5}{*}{ Acesso às informações } & 1 & É possível obter o Relatório Anual (RA) da Companhia via Internet? \\
\hline & 2 & O website dispõe de documentos relativos à governança corporativa? \\
\hline & 3 & $\begin{array}{l}\text { O website dispõe de apresentações para analistas ou dados que possibilitem projeções ope- } \\
\text { racionais e financeiras da empresa? }\end{array}$ \\
\hline & 4 & O website é bilíngüe e possui uma seção de Relações com Investidores? \\
\hline & 5 & $\begin{array}{l}\text { O website apresenta a estrutura acionária em detalhes, além das atas das últimas reuniões } \\
\text { do Conselho de Administração? }\end{array}$ \\
\hline \multirow[t]{5}{*}{$\begin{array}{l}\text { Conteúdo das informações } \\
\text { públicas }\end{array}$} & 6 & $\begin{array}{l}\text { O RA inclui uma seção específica dedicada à implementação de princípios de Governança } \\
\text { Corporativa? }\end{array}$ \\
\hline & 7 & O RA, website ou algum outro documento explica a remuneração global dos executivos? \\
\hline & 8 & As demonstrações são apresentados em US-GAAP ou IAS-GAAP? \\
\hline & 9 & $\begin{array}{l}\text { O RA, website ou algum outro documento inclui uma seção com estimativas de lucros ou } \\
\text { projeções de retornos financeiros (ROA, ROE, etc.)? }\end{array}$ \\
\hline & 10 & $\begin{array}{l}\text { O RA, website ou algum outro documento corporativo apresenta o valor adicionado/destruí- } \\
\text { do pelo negócio no período com base em alguma medida de lucro econômico? }\end{array}$ \\
\hline \multirow[t]{5}{*}{$\begin{array}{l}\text { Estrutura do Conselho } \\
\text { de Administração }\end{array}$} & 11 & $\begin{array}{l}\text { Os cargos de Diretor Executivo e Presidente do Conselho de Administração são ocupados por } \\
\text { pessoas diferentes? }\end{array}$ \\
\hline & 12 & A empresa possui um conselho de administração com 5 a 9 membros? \\
\hline & 13 & Mais do que $80 \%$ do conselho de administração é composto por conselheiros externos? \\
\hline & 14 & O conselho de administração possui mandato unificado de um ano? \\
\hline & 15 & $\begin{array}{l}\text { A empresa possui qualquer tipo de comitê do conselho de administração, evidenciado em } \\
\text { informações públicas? (Estatuto Social, Relatório Anual, website, etc.)? }\end{array}$ \\
\hline \multirow{5}{*}{$\begin{array}{l}\text { Estrutura de propriedade e } \\
\text { controle }\end{array}$} & 16 & A empresa emite apenas ações com direito a voto $(\mathrm{ON})$ ? \\
\hline & 17 & As ações preferenciais correspondem a menos do que $50 \%$ do total de ações? \\
\hline & 18 & O(s) controlador(res) possui(em) menos do que $70 \%$ do total de ações ordinárias? \\
\hline & 19 & $\begin{array}{l}\text { O excesso (DIF) de direitos de controle (\%ON) em relação aos direitos sobre o fluxo de caixa } \\
(\% \text { TA) do controlador é menor do que } 23 \% \text { ? }\end{array}$ \\
\hline & 20 & A empresa concede tag along aos detentores de ações preferenciais? \\
\hline
\end{tabular}

Fonte: Silveira (2004, p. 99)

Quadro 1 Questões para elaboração do índice de Governança Corporativa 
binária, que assume o valor de I quando a empresa faz parte da composição do IBX e zero quando não participa.

As demas variáveis de controle são aqueles determinantes da governança corporativa testados por Silveira (2004). Essas variáveis são resumidas a seguir:

- as portunidades futuras de crescimento (CREC) são calculadas pelo percentual acumulado do crescimento da receita operacional dos últimos 3(três) anos;

- a natureza da operação, medida pelo grau de tangibilidade (TANG) da empresa, foi calculada pelo ativo imobilizado bruto dividido pela receita operacional líquida;

- o tamanho da empresa [Log(REC)] foi calculado em termos nominais pelo logarítmo da receita operacional líquida;

- a variável binária que representa a emissão de ADR (ADR) assume o valor igual a I se a empresa possuir ADR e 0 em caso negativo;

- a variável binária que representa a adesão aos níveis de governança corporativa da BOVESPA (BOV) assume o valor igual a I se a empresa estiver listada nos níveis diferenciados de governança corporativa e 0 em caso negativo;

- a estrutura de propriedade $\left(O W N_{i}\right)$ e controle é representada por 3 variáveis: Direito de controle $(\mathrm{CON})$, calculado pelo percentual de ações ordinárias detidas pelo(s) acionista(s) controlador(es); Direito sobre o fluxo de caixa (PROP), calculado pelo percentual do total de ações detidas pelo(s) acionista(s) controlador(es); Disparidade entre direitos (DIF), calculado pela diferença entre CON e PROP;

- o desempenho (DESEMP) é representado por quatro variáveis: $\mathrm{Q}$ de Tobin $(\mathrm{Q})$, valor de mercado total da empresa (VF), lucro operacional dividido pelo ativo total (LOPAT), lucro antes dos juros, imposto de renda, depreciação e amortização, dividido pelo ativo total (LAJIRDA);

- o setor industrial (INDi) é uma variável binária construída para cada uma das 18 categorias analisadas e assume o valor igual a I quando a empresa assume um setor específico e 0 se a empresa pertencer a um outro setor;

- o controle da sociedade é uma variável binária construída para cada uma das seis categorais analisadas: propriedade privada estrangeira $($ IDENT $)$ ); propriedade privada nacional, detida por investidores não ligados à família fundadora da empresa $\left(\mathrm{IDENT}_{2}\right)$; propriedade de empresa nacional holding $\left(\mathrm{IDENT}_{3}\right)$; propriedade de empresa estrangeira holding (IDENT ${ }_{4}$ ); propriedade de empresa estatal holding $\left(\right.$ IDENT $\left._{5}\right)$; propriedade estatal (IDENT 6 );

- O índice de payout representa os dividendos pagos por ação divididos pelo lucro líquido por ação no final do exercício social e foi obtido junto ao sistema Economática (PAYOUT).

\section{RESULTADOS DA PESOUISA}

\subsection{Análise das regressões}

No momento da especificação do modelo econométrico para a análise da governança corporativa, uma importante questão deve ser levada em consideração: a causalidade reversa. Segundo Silveira (2004), que aborda amplamente esse problema, grande parte dos estudos, que utiliza as regressões múltiplas com equações isoladas, assume a governança corporativa como uma variável exógena que influencia o desempenho da empresa. Uma possível forma de se contornar a questão da causalidade reversa é com a aplicação de técnicas econométricas mais robustas, como a análise de equações simultâneas. Esse procedimento, embora recomendado, não é abordado no presente artigo. Entretanto, a preocupação com a endogeneidade está presente nas análises. Neste artigo, utiliza-se a análise de regressão múltipla utilizando-se, alternadamente, duas variáveis dependentes: a variável IGOV e a variável PART.

A primeira parte das análises assume como variável dependente a qualidade da governança corporativa (IGOV). Para isso, são processados, ao todo, 34 modelos de regressão. Por uma questão de limitação de espaço, são apresentados, neste artigo, apenas alguns desses modelos. Na segunda parte das análises, a variável dependente passa a ser a participação dos fundos de pensão (PART) nas empresas analisadas. Nesse caso, também não são mostrados todos os modelos processados.

\subsubsection{Análise da regressões utilizando IGOV como variável dependente}

A Tabela I apresenta os resultados da análise de regressão múltipla tomando como variável dependente o IGOV. O que difere os três modelos apresentados nessa tabela é a utilização alternada das variáveis COM, PROP e DIF. Como se pode observar, a variável PART apresenta uma relação negativa e estatisticamente significante a um nível de $1 \%$. Assim, de acordo com o resultado da regressão, quanto maior a participação acionária dos fundos de pensão na estrutura acionária da empresa, menor a qualidade da governança corporativa observada. A variável PART contempla a participação acionária total do fundo de pensão, ou seja, a somatória do total de ações ordinárias e das ações preferenciais. Quando observadas as trinta e quatro regressões considerando o IGOV como variável dependente, a variável PART apresentou significância a $1 \%$ em todas as regressões, prevalecendo a relação negativa com a qualidade da governança corporativa.

Esse resultado pode, à primeira vista, parecer contraditório com algumas argumentações encontradas na lite- 
ratura sobre governança. Daily et al. (1996), por exemplo, sugerem que $\mathrm{o}$ ativismo de investidores institucionais, particularmente dos fundos de pensão, pode levar a mudanças em alguns aspectos da governança, como o aumento de conselheiros externos, eliminação de alguns recursos que limitam processos de tomada de controle (takeover), separação dos cargos de Presidente Executivo e Presidente do Conselho de Administração etc. Essa linha de raciocínio poderia levar à hipótese de que quanto maior a participação acionária dos fundos de pensão, melhor seria a qualidade da governança.

A relação negativa, encontrada na presente pesquisa, pode ter uma explicação nas diferenças entre os mercados de capitais brasileiro e norte-americano no que diz respeito à concentração da propriedade. Quando o número de acionistas é muito elevado e a estrutura de controle é pulverizada, como no caso dos Estados Unidos, Monks e Minow (2004) argumentam que um acionista, isoladamente, não consegue exercer um monitoramento efetivo. Isso pode acontecer porque, mesmo que o investidor institucional seja proprietário de um grande bloco de ações, sua participação pode não ser representativa. Por isso, uma governança corporativa de boa qualidade poderia auxiliar esses investidores no processo de monitoramento.

$\grave{A}$ medida que os investidores institucionais aumentam sua participação no capital das empresas, Monks e Minow (2004) ponderam que a necessidade de monitoramento diminua, já que passa a existir um maior alinhamento de interesses com os demais acionistas controladores. Ao contrário, uma menor participação acionária pode estimular a demanda por maior nível de informação da empresa, gerando uma conseqüente meIhoria no processo de monitoramento e da governança corporativa. Nesse contexto, a participação acionária dos investidores institucionais poderia agir como um substituto a outros mecanismos de governança. Em estudos desenvolvidos no Brasil por Leal, Silva e Valadares (2002), Okimura (2003), Silva (2002), Silveira (2002), entre outros, pode-se constatar que a estrutura de propriedade no Brasil é predominantemente concentrada. Em função da concentração de propriedade característica das empresas brasileiras de capital aberto, o controle por parte dos investidores institucionais (como os fundos de pensão) pode acontecer mais facilmente. No mercado brasileiro, quando os fundos de pensão fazem parte do bloco de controle das empresas de capital aberto, freqüentemente eles participam ativamente do conselho de administração das empresas. Isso posto, parece razoável a constatação da relação negativa entre a participação acionária dos fundos de pensão e a qualidade de governança das empresas de capital aberto.

Nos três modelos apresentados na Tabela I $\boldsymbol{\theta}$, a variável BOV apresenta uma relação positiva e significante, a um nível de $1 \%$, em relação à qualidade da governança corporativa. Como esperado, esse resultado indica que as empresas listadas nos níveis diferenciados de governança corporativa da BOVESPA apresentam uma qualidade de go- vernança superior, quando comparadas com empresas que não aderiram aos níveis diferenciados de governança.

A variável direito de controle (CON), no Modelo I, apresentou significância a 5\%, com sinal negativo, revelando que quanto maior for o direito de controle do acionista controlador, menor é a qualidade da governança corporativa da empresa. A interpretação desse resultado deve considerar que, quanto menor o número de acionistas ordinários controladores e maior a sua participação no controle da empresa, menor o esforço empregado na promoção de uma melhor governança corporativa, pois os acionistas estariam mais informados sobre o dia-a-dia da companhia, contribuindo para reduzir o problema da assimetria de informação. Monks e Minow (2004, p. 180) discutem sobre qual seria a estrutura de acionistas ideal para uma empresa de capital aberto. Eles argumentam que o ideal é ter acionistas que possuam o conhecimento do negócio, habilidade e alinhamento de interesses, condições necessárias para viabilizar um nível ótimo de monitoramento. Argumentam, também, que os fundos de pensão, por apresentarem capacidade de investimento e visão de longo prazo, concentram os atributos essenciais para poderem ser considerados como candidatos naturais ideais para compartilhar o controle de uma empresa de capital aberto.

A variável LOGREC, no Modelo I, representativa do porte, apresenta uma relação positiva e significante a um nível de $5 \%$ em relação à qualidade da governança corporativa. O resultado obtido está em linha com a literatura, pois as empresas maiores, em tese, possuem maior capacidade em investir nos mecanismos de boas práticas de governança corporativa do que as empresas menores. Um outra explicação para essa relação pode estar associada à maior demanda das grandes empresas por recursos de longo prazo, como os oferecidos pelos fundos de pensão. As empresas brasileiras de maior porte, dessa forma, são incentivadas a promover melhores práticas de governança corporativa pois, assim, podem atrair mais recursos dos fundos de pensão.

Continuando no modelo I, o pagamento de dividendos representado pela variável PAYOUT apresenta relação positiva e significante a um nível de 10\% com a qualidade da governança corporativa.

As variáveis relacionadas às oportunidades futuras de crescimento (CREC), a natureza da operação (TANG), a identidade do acionista controlador (IDENT), assim como a participação das ações das empresas nos dois principais índices de referência no mercado de renda variável (PIBO e PIBX), não apresentaram significância em nenhum dos modelos analisados. Os resultados dos outros 31 modelos processados situam-se muito próximos aos obtidos nos Modelos I, 2 e 3.

Outro resultado que mostra boa significância estatística (a níveis de $1 \%$ e 5\%) é a relação positiva entre a variável ADR's e a qualidade de governança corporativa, sugerindo que as empresas que emitem Amercian Depositary Receipts no mercado americano mostram uma maior probabilidade de apresentar uma governança corporativa de maior qualidade. O resultado está em conformidade com a literatura porque a empresa que toma a decisão estratégica de fi- 
Tabela 1 || Análises de regressão - variável dependente: IGOV

\begin{tabular}{l|c|c|c|c|c|c}
\multirow{2}{*}{ Variável independente } & \multicolumn{2}{|c|}{ Modelo 1 } & \multicolumn{2}{c|}{ Modelo 2 } & \multicolumn{2}{c}{ Modelo 3 } \\
\cline { 2 - 7 } InterceptO & Coef. & Sig. & Coef. & Sig & Coef. & Sig. \\
\hline PART & $-0,40$ & 0,69 & 0,00 & 1,00 & 0,54 & 0,59 \\
\hline CON & $-3,45$ & $0,00 * * *$ & $-3,16$ & $0,00 * * *$ & $-2,73$ & $0,01 * * *$ \\
\hline PROP & $-2,15$ & $0,03 * *$ & & & & \\
\hline DIF & & & 1,37 & 0,17 & & \\
\hline CREC & & & & & $-4,54$ & $0,00 * * *$ \\
\hline TANG & $-0,05$ & 0,96 & $-0,12$ & 0,91 & $-0,57$ & 0,57 \\
\hline LOGREC & 1,12 & 0,27 & 0,66 & 0,51 & 0,11 & 0,91 \\
\hline ADR & 2,01 & $0,05 * *$ & 1,64 & 0,11 & 1,11 & 0,27 \\
\hline BOV & 2,46 & $0,02 * *$ & 2,28 & $0,03 * *$ & 3,14 & $0,00 * * *$ \\
\hline Q & 4,65 & $0,00 * * *$ & 4,26 & $0,00 * * *$ & 5,28 & $0,00 * * *$ \\
\hline PAYOUT & 1,26 & 0,21 & 1,65 & 0,10 & 2,02 & $0,05 * *$ \\
\hline PIBO & 1,76 & $0,08 *$ & 1,63 & 0,11 & 1,62 & 0,11 \\
\hline PIBX & 0,34 & 0,73 & 0,78 & 0,44 & 0,35 & 0,73 \\
\hline IDENT1ESTRANGEIRA & $-0,05$ & 0,96 & 0,62 & 0,54 & 1,20 & 0,23 \\
\hline IDENT2PRIVNACIONAL & 0,79 & 0,43 & 0,09 & 0,93 & $-0,19$ & 0,85 \\
\hline IDENT3NACHOLD & 0,69 & 0,49 & 0,08 & 0,94 & $-0,22$ & 0,82 \\
\hline IDENT4ESTRHOLD & 0,75 & 0,45 & 0,14 & 0,89 & $-0,17$ & 0,87 \\
\hline IDENT5ESTAHOLD & 0,90 & 0,37 & 0,19 & 0,85 & $-0,04$ & 0,97 \\
\hline IDENT6ESTATAL & 0,93 & 0,35 & 0,33 & 0,74 & 0,06 & 0,95 \\
\hline & 0,78 & 0,44 & 0,17 & 0,87 & $-0,17$ & 0,87 \\
\hline R2 & & & & & & \\
\hline R 2 ajustado & 0,55 & & 0,53 & & 0,61 & \\
\hline F & 0,46 & & 0,44 & & 0,54 & \\
\hline N & 6,14 & & 5,80 & & 8,11 & \\
\hline & 105 & & 105 & & 105 & \\
\hline & & & & & & \\
\hline
\end{tabular}

A variável dependente é o Índice de Governança Corporativa (IGOV). São utilizadas diversas variáveis independentes fixas: participação acionária dos fundos de pensão (PART); oportunidade futura de crescimento (CREC); natureza da operação (TANG); tamanho da empresa (Log(REC)); emissão de ADR (ADR); participação da empresa nos níveis diferenciados de governança corporativa da BOVESPA (BOV); Q de Tobin (Q); identidade do controlador - variáveis binárias do setor de atuação (IDENT); índice de payout (PAYOUT); participação da ação no Índice Bovespa (PIBO); participação da ação no Índice Brasil - IbrX (PIBX). São utilizadas variáveis independentes de forma alternada: direito de controle (CON); direito sobre o fluxo de caixa (PROP); diferença entre os direitos de controle e fluxo de caixa (DIF).

$$
\begin{aligned}
& \text { *** Significância a 1\% } \\
& \text { ** Significância a 5\% } \\
& \text { * Significância a 10\% }
\end{aligned}
$$

nanciar-se no mercado de capitais externo é incentivada a adotar melhores práticas de governança corporativa em função da necessidade de cumprir uma série de requisitos exigidos pela Security Exchange Comission (SEC)

\subsubsection{Análise das regressões utilizando PART como variável dependente}

Como destaca Silveira (2004), grande parte dos estudos assume a governança corporativa como exógena, exercendo influência sobre o desempenho das empresas. Levando em consideração essas possíveis questões de causalidade reversa, no presente artigo também se assume que a qualidade da governança atue como endógena, nesse caso influenciando a variável de participação acionária (PART) dos fundos de pensão. Procura-se, portanto, verificar se o fato de a empresa apresentar uma governan- ça de boa qualidade pode, eventualmente, servir de incentivo para que os fundos de pensão nela tenham elevada participação. Para analisar a influência das diversas variáveis independentes sobre a participação acionária dos fundos de pensão (PART), foram processados 18 modelos de regressão. Na Tabela $2 \boldsymbol{\theta}$, são apresentados alguns dos principais resultados. A exemplo da primeira parte das análises de regressão, não são apresentados todos os resultados por uma questão de limitação de espaço. De qualquer maneira, os resultados dos outros modelos são muito semelhantes aos apresentados.

Como se pode observar pela Tabela 2, a variável independente IGOV apresenta uma relação negativa e estatisticamente significante a um nível de I\%. Novamente, o argumento da substituição de uma boa governança pela maior participação ativista dos fundos de pensão, pode justificar 
Tabela 2 | Análises de regressão - variável dependente: PART

\begin{tabular}{l|c|c|c|c|c|c}
\multirow{2}{*}{ Variável Independente } & \multicolumn{2}{|c|}{ Modelo 4 } & \multicolumn{2}{c|}{ Modelo 5 } & \multicolumn{2}{c}{ Modelo 6 } \\
\cline { 2 - 7 } InterceptO & Coef. & Sig. & Coef. & Sig. & Coef. & Sig. \\
\hline IGOV & 0,29 & 0,77 & 0,11 & 0,91 & 0,21 & 0,83 \\
\hline COM & $-3,45$ & $0,00 * * *$ & $-3,16$ & $0,00 * * *$ & $-2,73$ & $0,01 * * *$ \\
\hline PROP & $-0,58$ & 0,57 & & & & \\
\hline DIF & & & $-1,02$ & 0,31 & & \\
\hline CREC & & & & & 0,55 & 0,59 \\
\hline TANG & 0,18 & 0,86 & 0,27 & 0,79 & 0,26 & 0,79 \\
\hline LOGREC & 0,38 & 0,70 & 0,55 & 0,58 & 0,44 & 0,66 \\
\hline ADR & 1,38 & 0,17 & 1,50 & 0,14 & 1,41 & 0,16 \\
\hline BOV & $-0,07$ & 0,94 & $-0,23$ & 0,82 & $-0,31$ & 0,76 \\
\hline Q & 1,27 & 0,21 & 1,14 & 0,26 & 0,93 & 0,35 \\
\hline IDENT1ESTRANGEIRA & $-0,68$ & 0,50 & $-0,84$ & 0,40 & $-0,74$ & 0,46 \\
\hline IDENT2PRIVNACIONAL & $-0,08$ & 0,94 & 0,11 & 0,91 & $-0,09$ & 0,93 \\
\hline IDENT3NACHOLD & $-0,19$ & 0,85 & $-0,01$ & 0,99 & $-0,18$ & 0,86 \\
\hline IDENT4ESTRHOLD & $-0,16$ & 0,87 & 0,02 & 0,99 & $-0,16$ & 0,88 \\
\hline IDENT5ESTAHOLD & $-0,19$ & 0,85 & $-0,01$ & 0,99 & $-0,21$ & 0,84 \\
\hline IDENT6ESTATAL & $-0,13$ & 0,90 & 0,04 & 0,97 & $-0,13$ & 0,90 \\
\hline PAYOUT & $-0,18$ & 0,86 & 0,01 & 0,99 & $-0,16$ & 0,87 \\
\hline PIBO & 0,00 & 1,00 & 0,00 & 1,00 & $-0,04$ & 0,97 \\
\hline PIBX & $-0,60$ & 0,55 & $-0,62$ & 0,54 & $-0,49$ & 0,63 \\
\hline R & 1,21 & 0,23 & 0,90 & 0,37 & 1,11 & 0,27 \\
\hline R ajustado & & & & & & \\
\hline F N & 0,21 & & 0,21 & & 0,21 & \\
\hline N & 0,05 & & 0,06 & & 0,05 & \\
\hline & 1,35 & & 1,40 & & 1,35 & \\
\hline & 105 & & 105 & & 105 & \\
\hline & & & & & & \\
\hline
\end{tabular}

A variável dependente é participação acionária dos fundos de pensão (PART). No Modelo 35, a variável independente é o Índice de Governança Corporativa (IGOV). No Modelo 36, as variáveis independentes são: Índice de Governança Corporativa (IGOV); participação da ação no Índice Bovespa (PIBO); participação da ação no Índice Brasil - IbrX (PIBX).Nos Modelos de 37 a 43, são utilizadas diversas variáveis independentes fixas: o Índice de Governança Corporativa (IGOV);crescimento da receita; oportunidade futura de crescimento (CREC); natureza da operação (TANG); tamanho da empresa (Log(REC));

emissão de ADR (ADR); participação da empresa nos níveis diferenciados de governança corporativa da BOVESPA (BOV); identidade do acionista controlador (IDENT); índice de payout (PAYOUT); participação da ação no Índice Bovespa (PIBO); participação da ação no Índice Brasil - IbrX (PIBX). São utilizadas variáveis independentes de forma alternada: direito de controle (CON); direito sobre o fluxo de caixa (PROP); diferença entre os direitos de controle e fluxo de caixa (DIF); Q de Tobin (Q); valor da empresa (VF) e lucro operacional próprio (LOPAT).

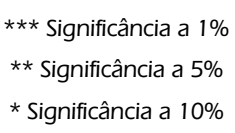

essa relação negativa. À medida que os fundos de pensão detenham parcela significativa das ações de uma empresa, seria desnecessário investir em mecanismos de governança já que seus interesses estariam alinhados com os dos outros acionistas. Nesses modelos 4, 5 e 6, é importante observar que apenas a variável IGOV se mostra significante para explicar a participação acionária dos fundos de pensão.
Nenhuma das outras variáveis se mostra estatisticamente significante. Esse fato leva a baixos coeficientes de determinação $\left(R^{2}\right)$ e ta mbém a baixos níveis de adequação $(F)$ dos modelos, sugerindo que a especificação de um modelo para explicar a participação dos fundos de pensão deva considerar outras variáveis que não foram incluídas no modelo.

\section{CONSIDERAC̣ÕES FINAIS}

O presente artigo mostra o importante papel que os fundos de pensão, como investidores institucionais, exercem sobre o mercado de capitais e sobre o desempenho das empresas. Na qualidade de grandes investidores, os fundos de pensão podem exercer de forma ativa o seu papel de monitor das atividades das empresas e, com isso, garantir uma remuneração adequada para seus investimentos. Os mecanismos de governança corporativa, assim, podem ajudá-los nessa tarefa. 
Nesse contexto, o objetivo principal do presente artigo é verificar se a participação acionária dos fundos de pensão exerce influência sobre a qualidade da governança corporativa das empresas. Além disso, em função de problemas de causalidade reversa sugeridos pela literatura, também é analisada a situação inversa, ou seja, procura-se analisar se a qualidade da governança corporativa influencia a participação acionária dos fundos de pensão.

A relação negativa entre essas variáveis levanta uma questão importante. Uma parte da literatura sobre governança sugere que o ativismo dos fundos de pensão poderia levar as empresas a melhorar seus mecanismos de governança. Entretanto, num mercado em que as participações acionárias são tão concentradas como no Brasil, parece ser razoável a idéia de que uma governança corporativa de qualidade possa ser substituída por uma maior participação acionária dos fundos de pensão.
Espera-se que esses resultados contribuam para um meIhor entendimento das políticas de investimentos dos fundos de pensão, bem como dos esforços que as empresas devam empreender para atrair os recursos desses fundos bem como de outros potenciais investidores institucionais. Como potenciais estudos futuros, pelo menos dois caminhos metodológicos podem ser seguidos. Um desses caminhos diz respeito à técnica estatística a ser empregada. No presente artigo, foi utilizada a técnica de análise de regressão múltipla. Em função de potenciais questões de causalidade reversa nos estudos sobre governança (SILVEIRA, 2004), sugere-se a utilização de outras técnicas que possam minimizar esse tipo de problema, como a análise de equações simultâneas ou a análise de equações estruturais. Um segundo caminho que pode ser seguido no futuro diz respeito à ampliação da série histórica dos dados e, assim, permitir-se a utilização de técnicas de análise como os dados em painel.

\section{Referências}

DAILY, C. M.; JOHNSON, J. L.; ELLSTRAND, A. E.; DALTON, D. R. Institutional investor activism: follow the leaders? Social Science Research Network, Oct. 1996. Disponível em: <http://papers.ssrn.com/sol3/papers.cfm?abstract_id=10299>. Acesso em: 26 jan. 2007.

DALTON, D. R.; DAILY, C. M.; ELLSTRAND, A. E.; JOHNSON, J. L. Meta-analitic reviews of board composition, leadership structure and financial performance. Strategic Management Journal, v. 19, p. 269-290, mar. 1998.

DENIS, D. K.; MCCONNELL, J. J. International Corporate Governance. Journal of Financial and Quantitative Analysis, v. 38; mar. 2003.

GILLAN, S.; STARKS, L. Relationship Investing and Shareholder Activism by Institutional Investors. Working paper, Austin: University of Texas, 1997.

JENSEN, M. C.; MECKLING, W. H. Theory of the Firm: Managerial Behavior, Agency Costs and Ownership Structure. Journal of Financial Economics, v. 3, p. 305-360, Oct. 1976.

Takeovers: Their Causes and Consequences. The Journal of Economic Perspectives, v. 2, n. 1, p. 21- 48, Winter 1988.

LEAL, R. P. C.; SILVA, A. L. C. da; VALADARES, S. M. Estrutura de Controle das Companhias Brasileiras de Capital Aberto. Revista de Administração Contemporânea, v. 6, ǹ. 1, jan.-abr. 2002.

MONKS, R. A.G.; MINOW, N. Corporate governance. Oxford: Blackwell, 2004.

OKIMURA, R. T. Estrutura de propriedade, governança corporativa, valor e desempenho das empresas no Brasil. 2003. Dissertação (Mestrado em Administração de Empresas) - Departamento de Administração da Faculdade de Economia, Administração e Contabilidade da Universidade de São Paulo, São Paulo, 2003.

SHLEIFER, A.; VISHNY, Robert. Large shareholders and corporate control. Journal of Political Economy, v. 94, p. 461-488, 1986.

SILVA, A. L. C. A influência da estrutura de controle e propriedade no valor, estrutura de capital e política de dividendos das empresas brasileiras. 2002. Tese (Doutorado em Administração de Empresas) - Insitituto COPPEAD de Administração, Universidade Federal do Rio de Janeiro, Rio de Janeiro, 2002.

SILVEIRA, A. Di M. Governança Corporativa, Desempenho e Valor da Empresa no Brasil. 2002. Dissertação (Mestrado em Administração de Empresas) - Departamento de Administração da Faculdade de Economia, Administração e Contabilidade da Universidade de São Paulo, São Paulo.

Governança Corporativa e Estrutura de Propriedade: Determinantes e Relação com o Desempenho das empresas no Brasil. 2004. Tese (Doutorado em Administração de Empresas) - Departamento de Administração da Faculdade de Economia, Administração e Contabilidade da Universidade de São Paulo, São Paulo:

BARROS, Lucas A. B. de C.; FAMÁ, Rubens. Estrutura de Governança e Desempenho Financeiro nas Companhias Abertas Brasileiras: um estudo empírico. Caderno de Pesquisas em Administração, v. 10, n. 1, jan.-mar. 2003.

WAHAL, S. Pension Fund Activism and Firm Performance. Journal of Financial and Quantitative Analysis, v. 31, n. 1, p. 1-23, mar. 1996.

\section{NOTA - Endereço dos autores}

Universidade Presbiteriana Mackenzie

Centro de Ciências Sociais e Aplicadas

Rua da Consolação, 930 - Consolação

São Paulo - SP

01302-090

R. Cont. Fin. • USP • São Paulo • v. 18 • n. 45 • p. 63 - 72 • set./dez. 2007 